\title{
Hemipelvectomy Type III
}

National Cancer Institute

\section{Source}

National Cancer Institute. Hemipelvectomy Type III. NCI Thesaurus. Code C157650.

A hemipelvectomy with the resection confined to the pubis. 